\title{
BOIS DE CARNAVAL
}

Iracema Barbosa (Université Rennes-2)

Este artigo aborda alguns aspectos referentes à realização do trabalho Bois de Carnaval, exposto quatro vezes, entre 2003 e 2009, em centros culturais de prestígio na França. Bois de Carnaval envolveu três anos de produção, integrando aspectos relativos à arte contemporânea e também à cultura popular. Apresentamos aqui três discursos distintos: o próprio, de artista, e os dos historiadores da arte Patrícia Corrêa e João Masao Kamita, que acompanharam tal produção e escreveram os textos publicados nos catálogos de duas exposições.

CARNAVAL; INSTALAÇÃO; ARTE CONTEMPORÂNEA.

BARBOSA, Iracema. Bois de carnaval. Textos escoIhidos de cultura e arte populares, Rio de Janeiro, v.10, n.2, p. 201-217, nov. 2013. 


\section{BOIS DE CARNAVAL}

Iracema Barbosa (Université Rennes-2)

This article discusses some aspects regarding the work Bois de Carnaval, displayed four times between 2003 and 2009 in prestigious cultural centers in France. Bois de Carnaval involved three years of production, integrating aspects related to both contemporary art and popular culture. We present here three different discourses: the artist's discourse, and art historians' Patrícia Corrêa and João Masao Kamita, who accompanied such production and wrote the texts published in the catalogs of two of the exhibitions.

CARNIVAL; INSTALLATION; CONTEMPORARY ART.

BARBOSA, Iracema. Bois de carnaval. Textos escoIhidos de cultura e arte populares, Rio de Janeiro, v.10, n.2, p. 201-217, nov. 2013. 
Em português, bois significa madeira. Madeira é associada à Matéria. Madeira-matéria-matter. São palavras que nos conduzem à presença do corpo e à origem das coisas.

Esse trabalho nasceu aqui, no Bois de Vincennes. Comecei colecionando galhos de árvores que estavam caídos no chão. Galhos finos, lisos, ásperos, longos e tortos. Selecionei-os, recolhi e organizei. Precisava reconstruir as coisas. Os fios coloridos me serviram para criar uma nova estrutura para esses galhos, como uma espécie de escrita que mistura memória e esperança. Sendo brilhantes, as fitas parecem estar úmidas.

Essas fitas, enquanto as amarrava, me traziam recordações das festas populares do Brasil, como a da Igreja do Bonfim, em que se oferecem fitas coloridas como voto de esperança. Recordações também das serpentinas lançadas durante o carnaval, cujas trajetórias acompanhamos no ar, antes que caiam no chão. Tais lembranças acompanharam os gestos repetitivos necessários para amarrar os galhos e me lembraram outros gestos, que conduziram a outras lembranças, dando a impressão de uma ação ritual.

Acredito que as relações entre esta exposição e o carnaval sejam meramente lúdicas, estando ligadas ao desejo de reorganizar coisas, de brincar, de dar um novo ritmo a um mundo tão acabado, tão definido, de fazer dançar a ordem deste mundo! Ao mesmo tempo, e isto já há 10 anos, meu trabalho permanece profundamente ligado a uma geometria que pretende colocar em evidência a desmedida das coisas, dando a elas precisamente um outro contexto.

(Texto escrito em Fontenay sous Bois, França, em 2003, impresso no convite da primeira exposição de Bois de Carnaval que realizei na La Galeru)

\section{A ORIGEM}

Bois de Carnaval é fruto de uma nova situação de vida e de trabalho, em um outro lugar. A travessia de um oceano, a mudança de um continente a outro, assim como o contato cotidiano com os museus - a possibilidade de ver e de rever uma mesma obra durante horas, e em diferentes ocasiões - transformam totalmente o trabalho de um artista. Mesmo a melhor reprodução de uma obra não substitui sua presença material, suas imperfeições, nossa experiência sensível com ela, e todas as surpresas que nos levam a viver. Esse contato com as obras possibilita a atualização de certas discussões solitárias de ateliê, a partir da análise da problemática e das soluções encontradas pelos artistas. É um diálogo que estimula o surgimento de novas experiências. ${ }^{1}$

Além disso, a tempestade do inverno de 1999 deixou no bosque de Vincennes, em Paris, uma grande quantidade de madeira caída no chão. Podiam-se 

Iracema Barbosa, Bois de Carnaval, 2000-2003, detalhe; foto: Benoît Pelletier

Para tal processo de confecção do trabalho, a demanda do corpo é intensa, pela força necessária para a coleta e transporte dos galhos ao ateliê (sobretudo no inverno), para serrar manualmente cada elemento em suas extremidades $^{2}$ e também pelo compromisso de horas sentada numa cadeira, com o corpo dobrado, para a costura das estruturas. É evidente que todo esse processo ritual de fazer se tornou parte integrante da forma do trabalho Bois de Carnaval, que a cada exposição se instala de um modo diferente, abrindo assim problemáticas específicas a cada montagem.

E é simplesmente de tal experiência que este texto trata. Pois a realização de um trabalho flexível, em que a disposição final só surge no lugar da exposição, enriquece certamente a experiência artística e orienta decisões a tomar. Isto é, a repetição de um trabalho cuja apresentação (disposição, formato, luz) varia em função dos diferentes locais de exposição introduz questões diversas para o artista, e o conduz a ser mais preciso no que diz respeito a suas proposições. Bois de Carnaval, desde sua realização, foi mostrado quatro vezes na França: a primeira na La Galeru, ${ }^{3}$ em 2003; a segunda, na capela de Saint-Gildas, ${ }^{4}$ em 2005; a terceira, no corredor do convento da Tourette, ${ }^{5}$ no Rhône, em 2007-2008; e a quarta, na Cité internationale des arts, em Paris, em 2009. 


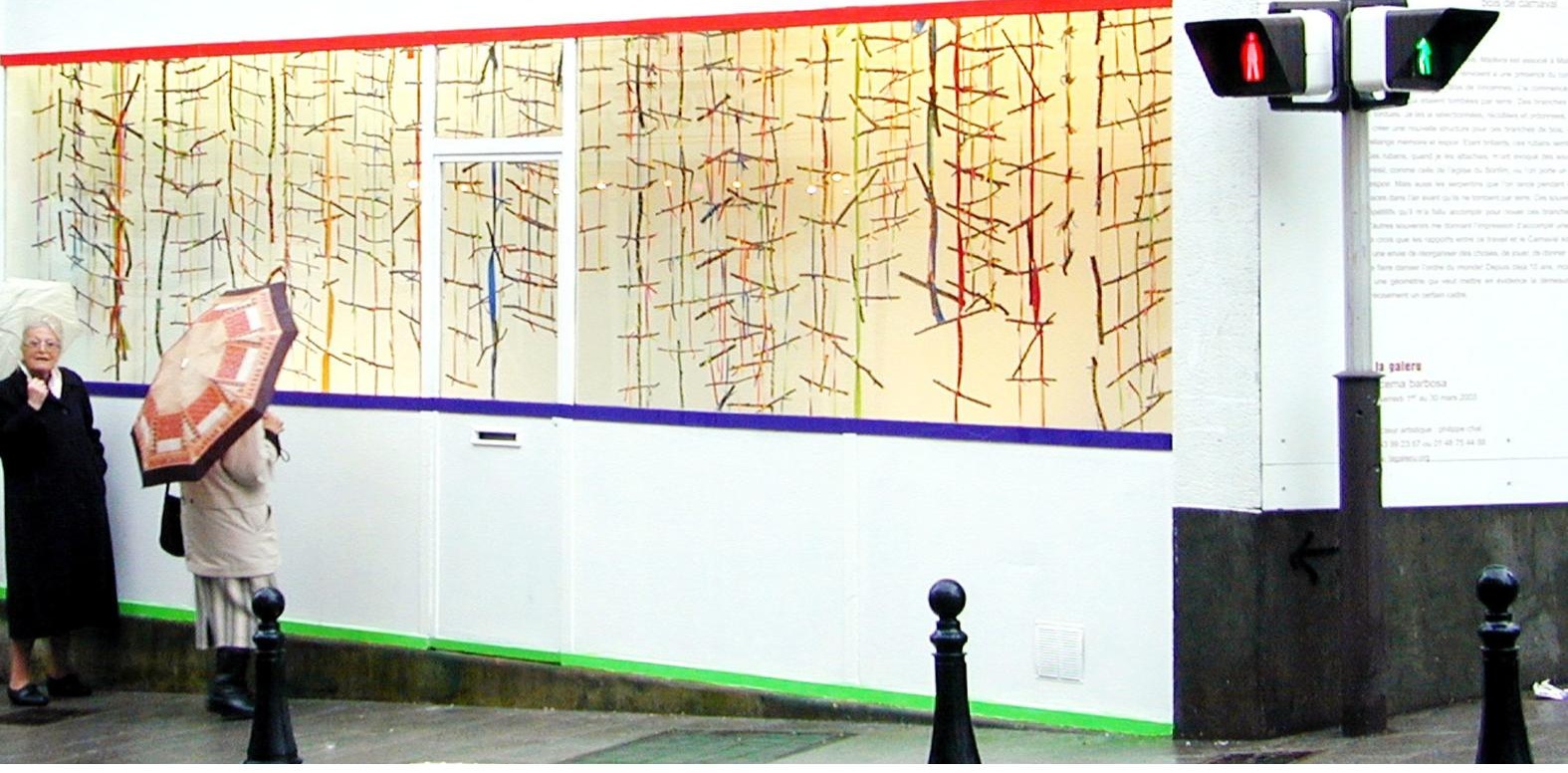

Iracema Barbosa, Bois de carnaval, 2003, La Galeru, Fontenay-sous-Bois, foto: Dominique Roy-le-Gac

\section{A PRIMEIRA MONTAGEM: LA GALERU, 2003}

La Galeru é uma espécie de galeria-vitrina, que expõe propostas artísticas diversas, num lugar de passagem de pedrestes, funcionando como uma vitrina comercial. A curadoria desse lugar trabalha fundamentalmente com projetos conceituais, que provoquem a atenção dos passantes. Trata-se de um pequeno retângulo, com 1,50m de profundidade por $7 \mathrm{~m}$ de comprimento, que constitui a parte envidraçada, situada a uma altura do chão que varia entre 1,20 e 1,60, começando no nível do peito do pedestre para cima.

Nessa primeira exposição de Bois de Carnaval, as estruturas foram suspensas de modo que o enquadramento da vitrina permitisse, da rua, uma visão do conjunto do trabalho através do vidro. As extremidades das estruturas foram colocadas fora do enquadramento da vitrina, o que acentuou a visão de seu conjunto. Mais do que todas as outras, essa montagem conduzia ao plano da pintu- 


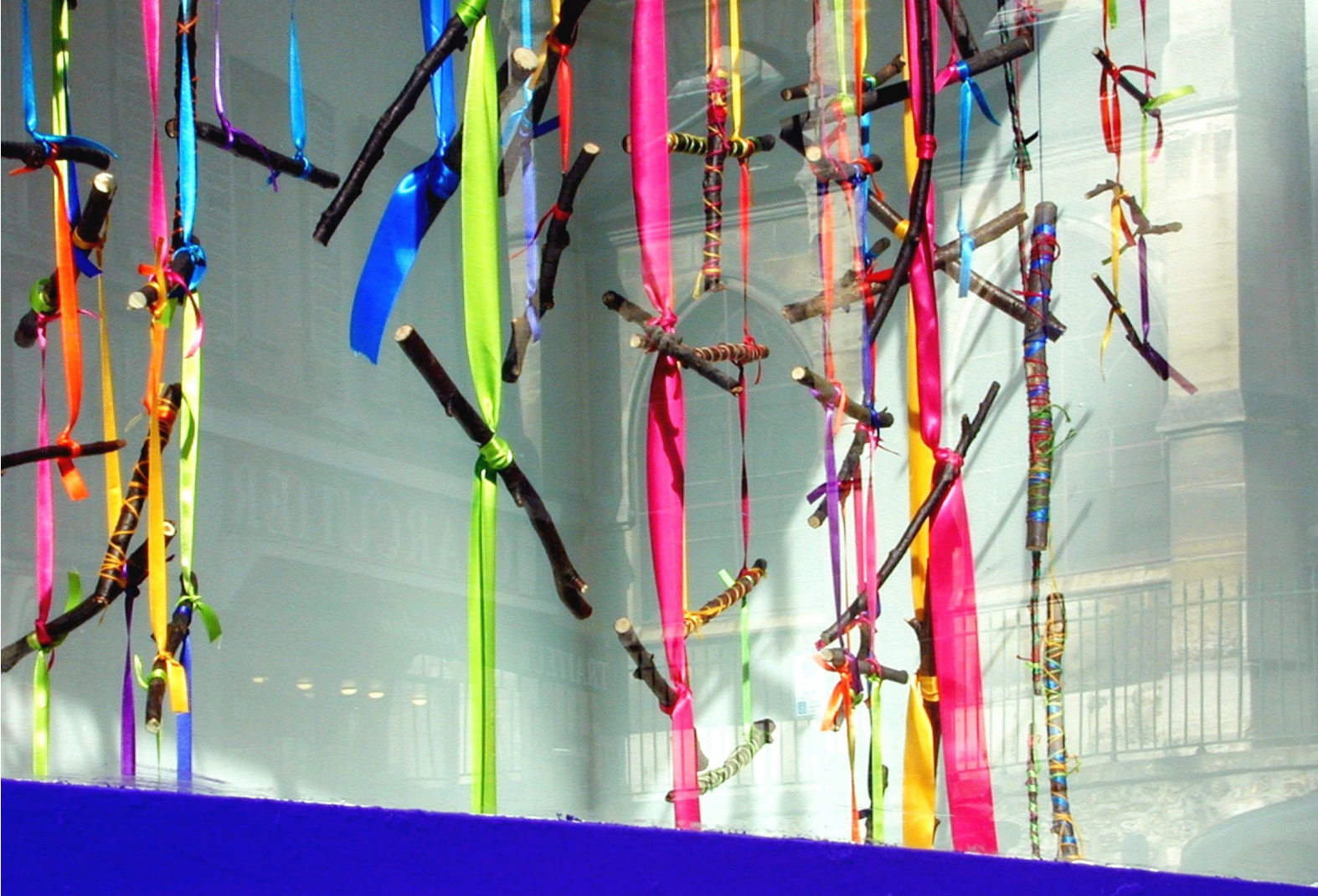

Iracema Barbosa, Bois de Carnaval, 2003, galhos costurados c/fitas de cetim e fios de seda e lã, 150 x 700 x $120 \mathrm{~cm}$, La Galeru, Fontenay-sous-Bois

ra, devido à presença do vidro retangular, no qual os elementos costurados e dispostos em diferentes planos e posições formavam um só plano. A repetição aleatória de poucas cores provoca uma leitura óptica do trabalho. Foi assim, devido a essa aproximação com a pintura, que tomei a decisão de pintar o exterior da Galeru, na parte que emoldurava a vitrina.

Aconteceu, porém, durante a exposição, outra questão relativa à modulação da luz naquela vitrina, que se associava aos reflexos da cidade e também à presença de sombras projetadas na parede do fundo da galeria. Percebi que, de fato, a madeira funcionava como suporte para a cor, e a luz, mais reduzida ao amanhecer e ao anoitecer, extraía do trabalho uma vibração ainda mais intensa das cores, presentes nas fitas de cetim e nos fios de seda e lã. Por outro lado, nessa montagem, senti falta das sensações produzidas pela proximidade dos diferentes materiais, estruturas e disposição variadas dos elementos, experiência que só era possível no interior da vitrina, ao qual as pessoas não tinham acesso. 


\section{A TERCEIRA MONTAGEM: CONVENTO DE LA TOURETTE, 2007- 2008}

A terceira montagem de Bois de Carnaval esteve intimamente associada à paisagem, particularmente às árvores, e ao fato de que, ao caminhar, podíamos atravessar o trabalho. Instalado num corredor de $23 \mathrm{~m}$ de comprimento por $3 \mathrm{~m}$ de largura, uma sucessão de estruturas foi suspensa no teto, ao longo de quatro metros, ao final da primeira reta do comprido corredor em forma de $L$, que conduz à biblioteca do convento de La Tourette. Assim, dispunha-se de um bom afastamento para apreendê-lo num primeiro momento, ao fundo, como uma estranha floresta que deveria ser atravessada para continuar o percurso até o outro lado. Via-se, no exterior, através do recorte estreito da janela, ao longo de todo o corredor, à altura dos olhos, os troncos das árvores enquadrados pela arquitetura monumental de Le Corbusier. Esse percurso no interior do trabalho dava a impressão de atravessarmos uma pintura. Pintura constituída pelo conjunto de gaIhos costurados com fios coloridos, criando a possibilidade de proximidade e de contato com os elementos, e, em consequência, favorecendo a percepção das diferentes costuras e cores que estruturavam tal floresta.

Iracema Barbosa, Bois de Carnaval, 2007-2008, Convento de la Tourette, L’Arbresle, foto: Benoit Pelletier

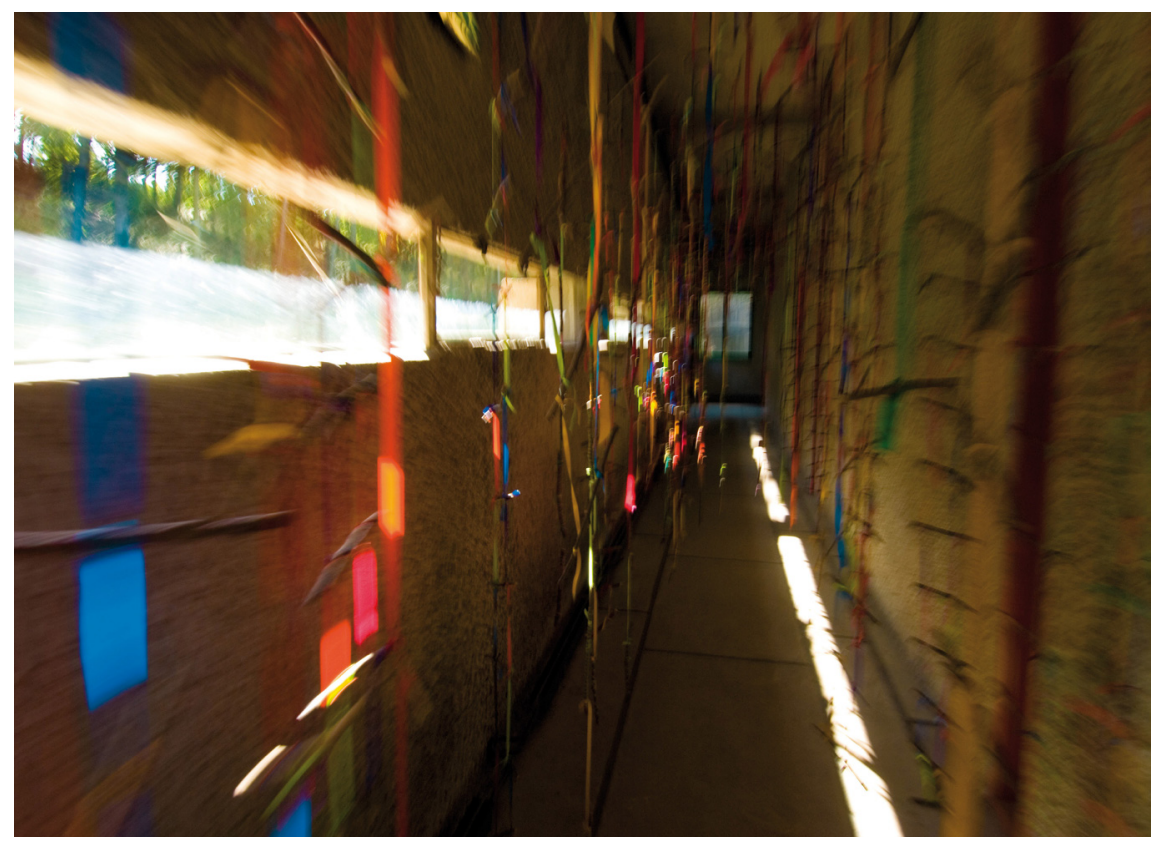


Na primeira visita ao convento, realizada no inverno que precedeu o da exposição, fiquei fascinada com sua arquitetura - as entradas de luz dos espaços construídos em concreto áspero, sua estrutura sólida (como a de uma fortaleza!) mergulhada naquela bela paisagem, do campo de vales amplos e arredondados do Beaujolais. Ao mesmo tempo, nosso caminhar dentro do convento se perde no labirinto, nas passagens, cortes, ângulos, vértices, entre as salas, oratórios, corredores, refeitório, cripta, etc. Le Corbusier traçou as aberturas de tal modo que, no interior da parte religiosa do convento, perdemos o senso de orientação. Assim, entre fascinada e intimidada, comecei as experimentações com meu trabalho naquele lugar, ${ }^{7}$ possibilitadas pelo fato de o convento de La Tourette estar em fase de resturação. Uma das questões mais complicadas que enfrentei, nesse contato de meu trabalho (frágil, leve, colorido e tão flexível) com aquela arquitetura tão imponente, foi instalá-lo sem que parecesse apenas um adereço e que funcionasse sim, apesar de sua modesta presença, na proposição de um diálogo estético com aquelas questões dali - os recortes da paisagem, a textura das paredes, as cores já presentes, e até as funções dos espaços. E foi sorrindo que ouvi o comentário provocador de um filósofo, em visita ao convento, depois de passar pelo corredor onde Bois de Carnaval estava instalado: "a gente se pergunta que animal seria capaz de deixar tal rastro".

Iracema Barbosa, Bois de Carnaval, 2009, Cité internationale des Arts, Paris; a: $2,40 m, \varnothing 3,50 m$

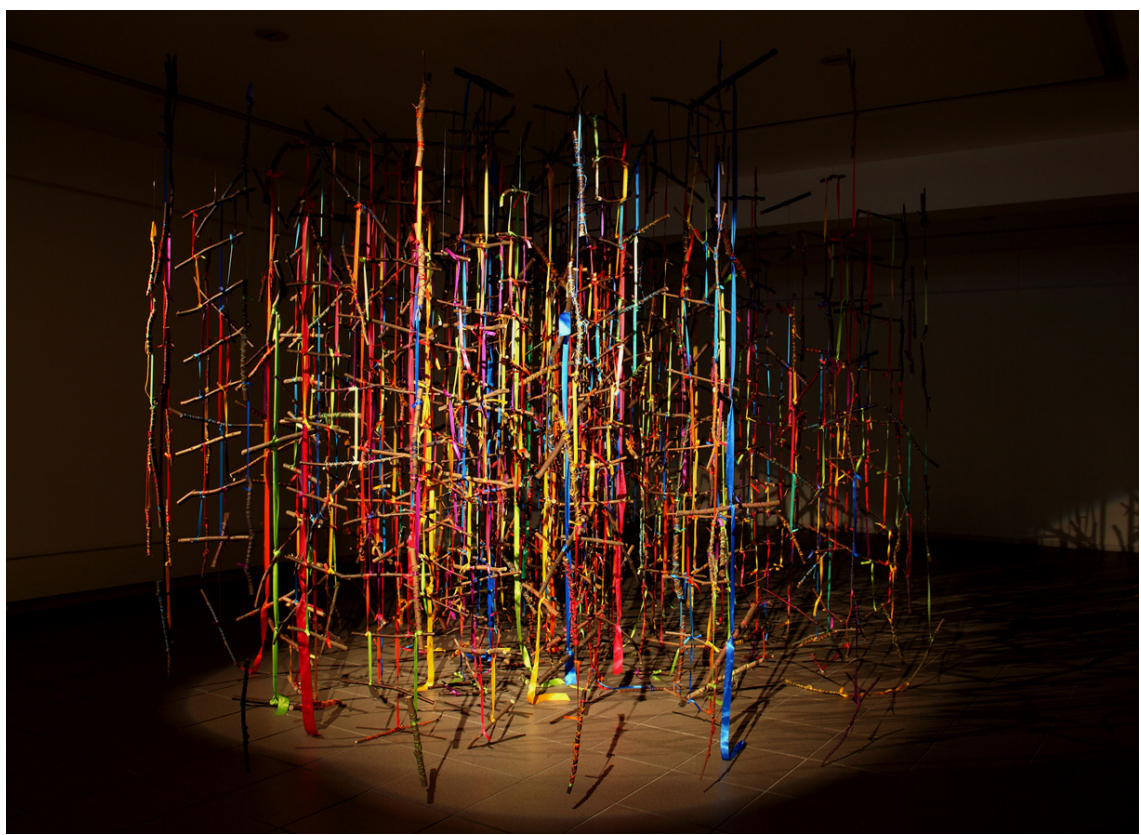


Foi pensando em alguém que tivesse as visões de arquiteto e de historiador da arte, estando ao mesmo tempo mergulhado nas questões formais enfrentadas na modernidade que João Masao Kamita foi convidado a escrever o texto tão costurado que acompanha o catálogo da exposição Démesurer, ${ }^{8}$ cujo recorte das partes relativas ao trabalho Bois de Carnaval estão disponíveis adiante.

\section{ANTES DO QUE SE DIZ}

Os dois textos ao final deste artigo, de Patricia Corrêa e de João Masao Kamita, revelaram para mim relações estruturantes na pesquisa que venho realizando nos últimos 20 anos no ateliêr. Me impressiona como os olhares externos, que na realidade passam por dentro do trabalho, podem potencializar o fazer do artista, tornando-o mais preciso. Como, por exemplo, os aspectos abordados por Patrícia Corrêa, que associam tais estruturas rudimentares à construção cinematográfica; ou, como formula João Masao Kamita, a confecção de um espaço flexível e sua relação com uma ordem geométrica. Não se trata aqui de comentar o comentário sobre o trabalho, mas de relevar o valor desse diálogo (quando ele de fato existe!).

Bois de Carnaval é, no meu percurso, um trabalho libertador, pois contribuiu para eliminar barreiras entre domínios tradicionais e onde o fazer perde sua urgência: não há mais forma a ser revelada. A ação constrói a forma sem a priori. As coisas do mundo entram no trabalho sem que se perceba (nesse caso, a tempestade disponibilizou a madeira, os fios da costura encontram-se nos armarinhos, e os gestos de amarrar e costurar fazem parte do cotidiano). Não importa mais se o trabalho tem duas ou três dimensões no espaço. O que conta é fazer ao longo do tempo, esticar a ação, o processo de criação, de modo que a visão do conjunto do trabalho não aconteça mais a priori.

As quatro montagens de Bois de Carnaval seguem uma mesma direção: potencializar a vibração da cor, provocando sua expansão no espaço.

O gesto repetido, cujo papel é o de confeccionar estruturas similares, acontece recolhido sobre a ação. Tal repetição obriga-me a estar presente na ação em si. E esta associação, entre repetição da ação e presença na ação, gera um estado meditativo e liberto de outras intenções. Se, num primeiro momento, uma motivação conduz à transformação do material - cortar, dobrar ou esticar, colocar em evidência certas qualidades plásticas e ópticas, reorganizar elementos -, durante a ação, qualquer objetivo de se atingir uma forma precisa se perde, propiciando um retorno à ignorância, possibilitando, assim, algo que nos surpreenda e que, ao mesmo tempo, nos conecte a tão antigas experiências... 


\section{NOTAS}

1 Entre outras exposições que me marcaram particularmente estão, em Paris: Picasso sculpteur, 2000, dialoguant avec l'art primitif, au Centre Georges-Pompidou; Mélancolie, génie et folie en Occident, 2005; e Brésil indien, les arts des Amérindiens du Brésil, 2005, no Grand Palais; Yves Klein, Corps, couleur, immatériel, 2006-2007; e Giacometti, L'Atelier d'Alberto Giacometti, 20072008, no Centre Georges-Pompidou; François Morellet, 2007; e Rodchenko, 2007, no musée d'Art moderne de la Ville de Paris; Anselm Kiefer, em 2007, e Richard Serra, em 2008, no Grand Palais (Monumenta). Em Londres: Bridget Riley, na Tate Britain, em 2003; Joseph Beuys, na Tate Modern, em 2005; Caravaggio, na National Gallery, em 2005. Descobrir o Espace dde l'Art Concret em Mouans-Sartoux. E as muitas visitas aos museus de Berlim, de Bilbao, de Bâle, de Veneza, de Florença, de São Petesburgo, de Barcelona e de Madri, entre 2000 et 2010

2 Foram realizadas em torno de 250 estruturas com oito a dez galhos cada, o que soma cerca de cinco mil cortes de madeira.

3 A exposição que se chamou Bois de Carnaval, foi realizada em 2003 com curadoria de Philippe Chat. O local da exposição, La Galeru, pertence à cidade de Fontenay-sous-Bois.

4 Chapelle Saint-Gildas, em Bieuzy-les-Eaux, no Morbihan, na Bretanha; tratase de uma gruta-capela. A exposição, com curadoria de Olivier Delavallade, foi realizada no contexto do projeto L'Art dans les chapelles.

5 Exposição Démesurer, no contexto de um projeto de residência, apoiado pelo projeto Odyssée do Ministério da Cultura da França e da Association des centres culturels de rencontre (ACCR) em 2007-2008, organizada por Jean-Louis Villeval.

6 O projeto l'Art dans les Chapelles foi criado e organizado por Olivier Delavallade.

7 O que certamente só foi possivel graças à generosidade de todos os envolvidos com aquele espaço: os irmãos dominicanos e toda a equipe do Centro cultural da Tourette, então dirigido por Jean-Louis Villeval, que se envolveu com todo o entusiasmo nesse projeto, tendo sido o responsável pela edição do catálogo da exposição Démesurer, realizada entre dezembro de 2007 e abril de 2008.

8 Démesurer contou com seis instalações de minha autoria, sendo uma delas Bois de Carnaval.

Iracema Barbosa é artista plástica, doutora em artes plásticas e pesquisadora do Laboratoire l'œuvre et l'image (EA 3208), pela Université Rennes-2.

Recebido em: 25/02/2013

Aceito em: 16/04/2013 


\section{FRUTOS DE COR}

\section{Patrícia Corrêa}

A ideia do enlace lúdico entre galhos e fitas, que constitui a intervenção de Iracema Barbosa na capela de Saint Gildas, surgiu há alguns anos, quando instalou seu ateliê em Fontenay sous Bois. A proximidade com o bosque, presença marcante na paisagem vivenciada pela artista, fez de suas árvores foco de interesse e material de trabalho. Era preciso perscrutar o novo ambiente, nele situar-se e torná-lo campo de ação, fazê-lo de algum modo seu. A observação das mudanças naturais de cor e forma, do nascimento e da queda de frutos, folhas e galhos, levou-a então a recolher restos desse processo, galhos secos que passou a cortar, organizar e, em seguida, amarrar com fitas de cetim e fios de lã coloridos.

Assim, deu a esses galhos nexo pessoal e afetivo - a lembrança de festas populares no Brasil onde nasceu e a referência a práticas artesanais ligadas ao seu círculo familiar. Mas também, e sem que isso contrarie as associações anteriores, deu-lhes nexo artístico, estético - criou estruturas de cor e luz, estruturas que podem ser pensadas a partir de experiências provenientes da pintura e do cinema, convertidas a uma interação produtiva com o espaço da capela. Segundo as palavras da artista, as mais de cem peças ali suspensas, singelamente iluminadas em meio à penumbra habitual do lugar, devem produzir as sensações da "luz-cor que se propaga no espaço escuro e das tramas que se projetam em sombras nas paredes".

$\mathrm{Na}$ trajetória de Iracema Barbosa, o início do engajamento na pintura foi praticamente coincidente com o engajamento no cinema. Começou a pintar em meados da década de 1980, quando trabalhava como assistente de direção em filmes. Algo que certamente as duas atividades lhe ensinaram a perceber foi a importância da luz, sua ação determinante na modulação da forma e da cor, o poder de espacialização intrínseco aos seus contrastes e variações, enfim, sua capacidade de dar coisas à visão. Há algo dessas descobertas na aparição cintilante de galhos e fitas, no modo como emergem dentro da capela. Sua oscilação visual depende do fato de serem estruturas que rebatem e ao mesmo tempo são transpassadas pela luz - mas se o primeiro tipo de sensação é mais próximo à pintura, o segundo tipo se aproxima principalmente do cinema.

As superfícies de cetim reluzem como "frutos úmidos" nessa floresta íntima, propagando cores brilhantes. Retomam, assim, uma característica da pintura - a tensão entre a tactilidade do suporte pintado e a opticalidade do fenômeno cromático, pois as fitas dão corpo e também ressonância às cores 
na capela, são materiais opacos e também agentes ópticos. Por outro lado, quando vazados pela luz tais elementos deflagram sombras sobrepostas, lançando mão de uma plasticidade típica do cinema - a capacidade de produzir densidade espacial a partir de um meio translúcido. As silhuetas projetadas nas paredes estabelecem diferentes noções de profundidade, apreendidas à medida que se caminha dentro da capela, portanto em um fluxo temporal. Como no cinema, a luz desenha nessa sala escura e, assim, articula um tempo próprio, distinto do tempo vivido fora dela.

Outro aspecto relevante da relação do trabalho com a pintura e com o cinema reside na questão do enquadramento, isto é, na percepção da ação de limitar como dinâmica produtiva do espaço. 0 interesse pelos galhos de Fontenay sous Bois nasceu da visão impressionante de sua nudez contra o céu ilimitado, da trama que copas de árvores sem folhas traçam no céu, dividindo-o em segmentos luminosos. Ao amarrar os galhos, a artista lida com a instabilidade e com a impermanência desses limites, volta a demarcar segmentos em um campo visual sob a evidência de sua precariedade. Tanto no cinema quanto na pintura, a força plástica do plano depende de sua capacidade de conjugar imanência e transcendência na articulação da estrutura pictórica ou da estrutura fílmica. Ou, dito mais simplesmente, nos dois casos estão em jogo, ainda é viável supor, a produção de sentido a partir de uma sintaxe de planos, onde os limites ou cortes distinguem elementos apenas para colocá-los em contato e tensão com outros elementos, portanto separam juntando, fecham abrindo, existem no próprio lance de sua superação.

Obviamente, tal dinâmica não se dá somente na estrutura interna desses meios, mas também no espaço vivencial em que o espectador os recebe. A instalação na capela procura dimensionar essa experiência ambígua do enquadramento, carregando sua geometria de vibração incerta, submetendo-a à dupla sensação da luz refletida e da luz vazada. A artista nos fala de cortes que transbordam, de um fim que é começo - como na matéria aparentemente morta dos galhos caídos que, no entanto, volta a imantar-se de vitalidade. Eis, em parte, o fascínio da ação artística: revelar o princípio de construção inerente à perecibilidade das coisas, tornar produtivos os nossos limites.

(Texto original de Patricia Corrêa, escrito em 2004, para o catálogo da exposição na capela de Saint-Gildas, projeto l'Art dans les Chapelles organizado por Olivier Delavallade) 


\section{COSTURAS E MEDIDAS}

\section{João Masao Kamita}

Tudo começa com a coleta. Reunir, guardar, acumular coisas (...) Uma coleção implica seleção e classificação, isto é, a busca de um certo princípio de identidade. 0 fato de serem da mesma espécie não assegura, porém, que exista entre elas uma conexão intrínseca. Se poderia mesmo pensar o contrário, que o fato de serem muitas, ou que um bom número seja do mesmo gênero, pudesse eliminar seu caráter singular, reduzindo-as a serem apenas um elemento de uma série.

Daí a presença desta trama, feita de laços, de nós, de amarras para ligar coisas. Fitas, linhas, cordas coloridas envolvem, amparam, seguram as peças coletadas, mas deixam em aberto seu modo de formalização. É no jogo tenso entre o elemento que se repete e a ordem flexível que o enlace promove que nós percebemos o paradoxo de uma disciplina geométrica em contato com uma pulsão afetiva.

Há, por certo, algo de primordial nesse ato de ligar, uma energia física sempre presente, como se tal articulação fosse um autêntico nó ontológico entre os seres. Esta "costura das coisas" faz pensar no historiador da arte Gottfried Semper que concebia a origem da obra de arte a partir do conceito da tectônica, como uma estrutura articulada delimitando um campo espacial (se trata de uma divergência evidente com a tradição clássica que via, como origem das artes plásticas, a latência da forma na matéria sólida; este conceito construtivo da tectônica nega a pulsão mimética que extrai a forma da matéria). A mesma coisa é válida para a arte da tecelagem, para carpintaria e para a construção da cabana primitiva de fibra vegetal e madeira. São estruturas leves e articuladas que tendem à imaterialidade e valorizam a junção dos elementos constituintes. No limite, se trataria de uma forma que se amolda às condições existentes, quer elas sejam físicas, psicológicas, corpóreas, enfim, ao que temos no lugar.

Contudo, o desafio da artista é intervir num espaço previamente carregado de intenção artística. Não se trata de um cubo branco convencional, mas da arquitetura de Le Corbusier, de um Le Corbusier que tinha recém-descoberto o espaço do sagrado, no qual os homens anseiam comunicar terra e céu. Nesse todo voltado para o interior, o arquiteto arma uma verdadeira tensão visual que percorre todo o edifício, forçando os limites dialéticos entre repetitivo e singular, entre geometria cartesiana e emoção plástica, matéria e luz, linha reta e curva, plano e profundidade. É justamente aí que reside o ponto 
de contato entre as instalações de Iracema Barbosa e a obra de Le Corbusier: na troca incessante de ordens divergentes (...)

Bois de Carnaval traz a floresta culturalizada para o interior do prédio, mas de modo inverso, pois caem soltos do teto, roçando as ásperas paredes do longo e estreito corredor. A luz em movimento que entra das frestas rasgadas na áspera parede, acentua a vibração cromática e o jogo de luz e sombra tornando o espaço ainda mais indecidível (...)

As instalações de Iracema Barbosa nos colocam na reflexão sobre a condição dramática da presença na contemporaneidade, que parece admitir somente arranjos precários, conexões provisórias. Mas isso não significa, e é isto que a artista demonstra, que arte deva se conformar a um modo de existir sem substância, como se as formas de experiências corporais e de vida não fossem mais possíveis.

(Fragmentos do texto de João Masao Kamita, escrito para o catálogo da exposição Démesurer, realizada no Convento de La Tourette, projeto OdysséeACCR, 2007-2008) 
